\title{
An Exploratory Study of an Undefined Acquired Neuromotor Speech Disorder within the Context of the Four Level Framework for Speech Sensorimotor Control
}

\author{
Dunay Schmulian, Anita van der Merwe and Emily Groenewald \\ Department of Communication Pathology \\ University of Pretoria
}

\begin{abstract}
In this study, the speech of a 28-year-old male with acquired brain injury and who presents with an undefined neuromotor speech disorder which cannot be categorised as either apraxia of speech or dysarthria, is described. Voice onset time, vowel duration, utterance duration and vowel formant analyses were done acoustically. A perceptual analysis and intelligibility rating were also executed. The subject was found to present with unique perceptual symptoms, intelligible speech, prolonged sound duration and distorted vowel quality. The results are interpreted within the context of the Four Level Framework of Speech Sensorimotor Control (Van der Merwe, 1997).
\end{abstract}

\section{OPSOMMING}

In hierdie studie word die spraak van 'n 28-jarige manlike persoon met 'n verworwe hoofbesering, en met 'n ongedefinieerde neuromotoriese spraakafwyking wat nie as verbale apraksie of disartrie geklassifiseer kan word nie, beskryf. Stemaanvangstyd, vokaalduur en uitingduur, sowel as vokaalformant-analises is akoesties uitgevoer. ' $n$ Perseptuele analise en verstaanbaarheidstoets is ook toegepas. Die proefpersoon het gepresenteer met unieke perseptuele simptome, verstaanbare spraak, verlengde klankduur en distorsie in vokaalkwaliteit. Die resultate word binne die konteks van die Viervlak Raamwerk van Sensories. Motoriese Spraakkontrole geïterpreteer (Van der Merwe, 1997).

KEY WORDS: neuromotor speech disorders, Four Level Framework.

To appreciate the speech production process and its overwhelming complexity, one only has to study the vast amount of literature attempting to capture the essence of this process and its concomitant pathologies. The identification of phases involved in this process remains problematic and yet a clear differentiation is necessary to comprehensively define sensorimotor speech disorders. McNeil and Kent (1987) state that the assumptions underlying neurogenic pathologic populations need to be reconsidered. The reason being that there are existing pathologies that cannot be satisfactorily explained by the traditional conception of the speech production process. The origin of the traditional speech production model can be traced to the three stages involved in motor skill namely the encoding, programming and execution of body movements. This model was projected onto the speech production process and traditionally three stages have been distinguished: linguistic encoding, articulatory programming and execution of movements (Darley, Aronson \& Brown, 1975). Aphasia is seen as a deficit on the highest level of the model namely linguistic encoding, apraxia of speech (AOS) as an impairment on an articulatory programming level and dysarthria as a deficit on the level of execution of movement.

Reconsideration of our traditional conception, would question and evaluate the validity of the three level model. According to Van der Merwe (1997) a four level framework should be adopted on the grounds of differential neurophysi- ological involvement of the various brain structures involved in neuromotor function and that, therefore, a distinction should be drawn between motor planning and motor programming based on these neurophysiological grounds. The so-called association areas are believed to be responsible for motor planning (Allen \& Tsukahara, 1974; Brooks, 1986; Marsden, 1984). The motor association areas, namely the premotor cortex (lateral area 6), the supplementary motor area (medial area 6 ) as well as the prefrontal and parietal association areas, are indicated in motor planning. Brooks (1986) posits that the caudate circuit of the basal ganglia is part of the "higher" hierarchical level in the sense that it enables the high level plans to be translated into motor action.

The neural areas involved in motor programming comprises the basal ganglia, the lateral cerebellum, the SMA, the motor cortex and the fronto-limbic system. It is generally accepted that the basal ganglia and the lateral cerebellum in particular are involved in programming and these parts perform complementary functions. The exact role of each, however, is not known. There are indications that the basal ganglia has a more "sophisticated" role to play than the cerebellum. The motor cortex, the lower motor neurons, peripheral nerves and motor units are the neural structures involved in the execution phase of the hierarchy (Van der Merwe, 1997). Thus differentiation between the functions of the neuromotor areas indicate involvement 
on three motor levels, namely planning, programming and execution.

Speech production is also a motor act and it is probable that the same three motor phases can be distinguished. Language planning is, however, also essential in speech. This implies an addition to the traditional three stage model of linguistic encoding, programming and execution of speech movements, resulting in a four level model / framework consisting of one pre-motor stage namely linguistic-symbolic planning and three motor stages namely motor planning, motor programming and the execution of movement (Van der Merwe, 1997).

Where the terms motor planning and motor programming were used interchangeably in the traditional speech production models (Lapointe, 1982; Itoh \& Sasanuma, 1984), Van der Merwe (1997) draws a clear distinction. Motor planning is described as the recall of a core motor plan for each phoneme in the planned unit, sequential organization of the motor goals identified for each phoneme, adaptation of the core motor plans within the context of the planned unit and specification of motor plan subroutines. Motor programming on the other hand, entails the selection and sequencing of motor programs for movements of the muscles of articulatory structures. Specifications of muscle tone, movement direction, force, range, rate and the mechanical stiffness of joints required by the planned movement, are specified by the motor program (Van der Merwe, 1997).

Needless to say, a four stage model such as Van der Merwe's Framework, holds vast implications for the classification of the different neuromotor speech disorders. It advocates a fourth grouping of disorders not yet identified or described clearly in the literature, namely a pure motor programming disorder. AOS seems to fit the definition of a motor planning disorder, dysarthria due to basal ganglia, cerebellar and motor cortex lesions would represent coexisting problems in both motor programming and execution and Lower Motor Neuron Dysarthria indicates a disorder in the execution of movement (Van der Merwe, 1986; 1997; Van der Merwe, Groenewald, Brittz \& Grimbeek, 1995). The questions arise whether a pure motor programming speech disorder exists, and also what the symptomatology of such a disorder will entail. The above-mentioned definition of programming predicts that symptoms resulting from such a disorder would probably be sound distortions, defects in speech rate, or problems in the initiation of movement. These would occur in the absence of muscle tone disorders or involuntary movements which induce dysarthria (Van der Merwe, 1997).

The differentiation between different speech disorders is not always clear cut. Symptomatology may differ and yet if symptoms correspond, it does not necessarily imply or indicate a homologous problem. One way of addressing the essence of motor speech disorders is by manipulating certain contextual factors such as sound structure and the articulatory characteristics of the utterance and thereby placing differential demands on the motor system. By determining and comparing reactions to variation in speech context, more insight could be gained into the nature of motor speech disorders and it can contribute towards differentiating disorders in the different stages of the motor process (Van der Merwe, 1986). This same method is applied in the present study. If context sensitivity is displayed, the pattern of sensitivity can be compared to that of other subjects with neuromotor speech disorders who were studied in previous research (Van der Merwe, 1986;
Brittz, 1994; Van der Merwe, et al., 1995).

The aim of this study is to describe the acoustic and perceptual symptoms and also the effect of variation of certain contextual factors on the speech of a person with an undefined acquired neuromotor speech disorder. Based on the symptomatology, his speech disorder cannot be classified as either apraxia of speech, dysarthria or a combination of the two. We aim to describe the symptoms within the theoretical context of the Four Level Framework (Van der Merwe, 1997), where it might be representative of an impairment on the level of motor programming in the speech production process.

\section{METHOD}

\section{GOALS AND SUBGOALS}

The main goal is to describe the perceptual and acoustic speech symptoms of a speaker with an acquired neurogenic speech disorder which does not fit the traditional classification of dysarthria or AOS or a combination of both. The symptomatology will be explained within the theoretical context of the Four Level Framework.

\section{Subgoals}

- To identify symptoms occurring and to determine similarity with symptoms that are categorised under dysarthria or AOS in world literature, through a perceptual analysis (perceptual analysis 1 ).

- To describe certain temporal characteristics of the subject's speech through acoustic analysis of nonsense units that are systematically varied in sound structure and articulatory characteristics and to determine the possible reaction to manipulation of context (acoustic analysis 1 ).

- To rate the intelligibility of words on a closed set format (perceptual analysis 2).

- To analyze deviant vowel production as identified by the intelligibility test (acoustic analysis 2 ).

\section{RESEARCH SUBJECT AND LISTENER PANELS}

\section{Research subject.}

The criteria for the research subject were:

- The subject must display an acquired neuromotor speech disorder which does not fit the classification of either apraxia of speech or dysarthria or a combination of both, as diagnosed by an experienced speech pathologist specialising in the field of neuromotor speech disorders. The subject should not display the core symptoms of these disorders namely, effortful speech with self-initiated trials to correct errors, islands of error-free speech or sound substitutions and distorted sound substitutions as can be expected from AOS or muscle tone abnormalities and involuntary movements which cause consistent distortion in dysarthria (McNeil, Robin \& Schmidt, 1997: Darley, et al., 1975; Yorkston, Beukelman \& Bell, 1988).

- Normal auditory comprehension and memory should be present to ensure comprehension of instructions.

- Reading skill must be adequate to read a passage orally.

The selected research subject is a 28-year-old Afrikaans speaking male. He has a head injury resulting from a motorcycle accident in 1989. He exhibited an indriven frac- 
ture ( $3 \mathrm{~cm}$ by $3 \mathrm{~cm}$ occipital). Scan information further showed bleeding in the left motor cortex. He remained in a coma and on a respirator 7 weeks post-trauma. He presented with right hemiplegia and spasticity after regaining consciousness. He received intensive physiotherapy which belped to reduce the hemiplegia to near normal. He received intensive speech and language therapy at the Speech-, Language and Hearing Clinic at the University of Pretoria for seven years post accident. The Western Aphasia Battery (Kertesz, 1982) was performed yearly and overall scores stabilised and formed a plateau from 1991 onwards. He obtained an aphasic quotient of 94.2 classifying him as a mild anomic aphasic. The Pragmatic Protocol (Prutting \& Kirschner, 1983) also showed fewer inappropriate behaviours since 1992. Speech intelligibility was assessed with the "Afrikaanse Toets vir Spraakverstaanbaarheid" (Klopper, 1983) and scores prior to dismissal were respectively $83 \%$ and $91 \%$ for intelligibility on single words and sentences. Other assessments include screening for closed head injury as well as tests identifying and rating severity of dysarthria (Van der Merwe, 1985) and AOS (Van der Merwe, 1986). His speech could not be classified as either purely apraxic or dysarthric or a combination of the two.

\section{Listenerpanels}

Two listener panels were utilized in the study. The first was a sophisticated panel which did the perceptual analysis of characteristic symptoms as this required specialised skills and a semi-sophisticated panel which did the intelligibility scoring as these scores would be representative of intelligibility for the general population.

The criteria for the sophisticated listener panel stipulated that members should be experienced speech language pathologists specialising in the field of neuromotor speech disorders and the perceptual analysis of neuromotor speech disorders. The selected panel consisted of two speech pathologists as the analyses were done by consensus.

The criteria for the semi-sophisticated listener panel stipulated that the members should be Afrikaans-speaking and have knowledge of normal and abnormal speech production. The selected panel consisted of six final year Communication Pathology students at the University of Pretoria.

\section{MATERIAL}

\section{Perceptual analysis: The symptom profile}

A list of possible symptoms indicative of neuromotor speech disorders was compiled, using symptoms listed in the literature on AOS and the different dysarthrias (Kent \& Rosenbek, 1983; Yorkston, et al., 1988; McNeil, et al., 1997, Darley, et al., 1975). The sophisticated listener panel indicated presence or absence of the symptom in the subject's tape recorded speech. The subject was recorded while reading a phonetically balanced passage ("In die Wildtuin") which was developed for research purposes.

\section{Acoustic analysis 1: Voice-onset-time, vowel duration and utterance duration}

The material for this analysis was duplicated from a similar, but more comprehensive study by Van der Merwe (1986) in which the influence of certain contextual factors on temporal features were studied. The material consists of groups of nonsense syllables that differ in sound structure and articulation characteristics. Five sound structure groups and four articulation characteristic groups can be distinguished. The sound structure groups differ in length, sequence of consonants (C) and vowels (V), as well as the number of phonemes in every utterance. The articulation groups dif fer in place and manner of articulation. Nonsense syllables make the strict control of sound structure and articulation characteristics possible. The material consisted of 20 nonsense units. Each unit was repeated six times and the five most constant repetitions were analysed. Table 1 contains the nonsense units in their respective articulation characteristics and sound structure groups.

\section{Perceptual analysis 2: Intelligibility test}

In order to ascertain intelligibility on a single word level, a list of twenty words from the "Afrikaanse verstaanbaarheidstoets vir disartriese sprekers" (Klopper, 1983) were applied. Listeners had to select and circle the appropriate word out of a closed set of nine similar sounding words.

\section{Acoustic analysis 2: Formant values}

In order to ascertain differences from normal formant values of vowels, as obtained from a previous study (Van der Merwe, Groenewald, Van Aardt, Tesner \& Grimbeck, 1993), the two most deviant vowels (as determined during perceptual analysis 2), namely [a] and [0], were analysed. The vowels were taken from the phonetically balanced passage which the subject read. The contexts in which these vowels occurred, were controlled by analyzing identical words or vowels with similar phonetic contexts.

TABLE 1: Nonsense units slotted into sound structure and articulation characteristics

\begin{tabular}{|c|c|c|c|c|c|}
\hline $\begin{array}{c}\text { SOUND } \\
\text { STRUCTURE }\end{array}$ & \multicolumn{5}{|c|}{ ARTICULATION CHARACTERISTICS } \\
\hline 1 & 1.1 babe & 1.2 bobe & 1.3 dade & 1.4 & $\mathrm{~d} \supset \mathrm{d} \varepsilon$ \\
\hline 2 & 2.1 bate & 2.2 bot $\varepsilon$ & 2.3 dake & 2.4 & dok $\varepsilon$ \\
\hline 3 & 3.1 batef & 3.2 botef & 3.3 dakef & 3.4 & dokef \\
\hline 4 & 4.1 bat & 4.2 bot & $4.3 \mathrm{dak}$ & 4.4 & dok \\
\hline 5 & 5.1 batefup & 5.2 botefup & 5.3 dakefup & 5.4 & dokefup \\
\hline
\end{tabular}




\section{APPARATUS}

Recording equipment for acoustic analysis 1 and $2: \mathrm{AKG}$ D $1200 \mathrm{E}$ short distance, directional microphone, a Nakamichi versatile cassette system and a TDK 90 minute magnetic cassette.

Analysis equipment for acoustic analysis 1: A Nakamichi 550 cassette was used to send the speech signal to the Kay DSP Sona-Graph Model 5500 where the speech signal was analysed by a digital signal processor. The speech was monitored with two JBL Pro 3 loudspeakers. The speech signal was displayed on a NEC Multisync 2 display screen, where the time cursors and a time axis were used to obtain all required measurements. To permit comparison to controls used by Brittz (1994), it was decided to use the identical analysis set-up and recording equipment.

Analysis equipment for acoustic analysis 2: The Computer Speech Laboratory (CSL) Model 4300 B of Kay Elemetrics Corporation was used because of its automatic formant tracing facility.

\section{PROCEDURE}

As it was an exploratory study, it was decided to commence the study by allowing the sophisticated listener panel to listen to a tape recorded speech sample of the subject to determine the diagnostic, neurogenic speech disorder category of the subject (perceptual analysis 1) by identifying the symptoms in his speech.

It was then decided to study the influence of variation in contextual factors, on the three temporal features previously mentioned, and to determine whether context sensitivity occurred (acoustic analysis 1). The data of normal control speakers studied by Van der Merwe, et al. (1993) and Brittz (1994) were used for comparative purposes. A semi-sophisticated listener panel's intelligibility rating and subjective diagnostic interpretation of the subject's speech was obtained. It was also required of this panel to identify sounds perceived as deviant from normal production (perceptual analysis 2 ).

The analysis of the formants of the subject's vowels [a] and [0], was executed as a result of the semi-sophisticated listener panel's perception that vowels were more deviant from normal production than consonants, particularly [a] and [o] (perceptual analysis 2).

\section{DATA ANALYSIS}

\section{Perceptual analysis 1: Symptom profile}

Symptoms of neuromotor speech disorders, as taken from the literature, were tabulated to form the starting point from where to examine all other results. The presenting symptoms were identified by applying the method of analysis through consensus of two sophisticated listeners.

\section{Acoustic analyses}

Training in the use of the analysis equipment, and the technique involved in acoustic measurements, was received from a researcher who had obtained a masters degree in the field and who is an experienced user of the equipment. The analysis was done by the first author and problematic analyses received consultation from the above-mentioned researcher.

\section{Acoustic analysis 1: Voice-onset-time, vowel duration} and utterance duration

Three temporal speech parameters, namely voice-onsettime (VOT), vowel duration (VD) and utterance duration (UD) were measured. Identical analysis set-ups were used for all three speech parameters. A twofold analysis of the speech signal was displayed simultaneously on the screen, with the sound wave on the upper half of the screen and a broadband spectrogram of the speech sound energy between 0 and $8000 \mathrm{~Hz}$ on the lower screen. With VOT, VD and UD, the two representations were constantly compared to increase reliability of the measures.

VOT of the initial voiced plosives was measured. The initial consonant was selected for analysis as it indicates more sensitivity towards contextual factors (Ingrisano \& Weismer, 1979). The VOT is measured from the plosive to the commencement of the first vertical striate on the spectrogram that represents glottal pulsing (Lisker \& Abrahamson, 1964). The commencement of the plosive was regarded as the graphic nil point and the voice onset after the plosive obtained a positive notation, while the voice onset preceding the plosive was noted as negative.

The range of VOT was calculated for each category, in other words, the biggest negative, or the smallest positive value was recorded as borders of the range. The criteria for normal VOT, namely $-180 \mathrm{msec}$ to $+15 \mathrm{msec}$ (Van der Merwe, 1986; Brittz, 1994) was applied to the range of VOT.

The speech parameter VD was measured during the production of a short vowel after the initial plosive. The transition between a consonant and the following vowel provides a context for the greatest variance in acoustic parameters (Gay, 1979). The speech parameter UD was measured as the first CVCV unit of each utterance and CVC in the case of structure 4 units. Measurement started from the commencement of the first vowel, i.e., the plosive where a positive value was obtained, or voice onset in cases of negative VOT values. The processing of VD and UD were both conducted as follows:

* The median values of the five repetitions of the nonsense syllables were calculated using non-parametric statistical analysis in order to make comparison with the control data possible. The control data was taken from a study by Brittz (1994) who used the same material and did the study in the same laboratory. The control subject used in that study was a normal male speaker in the same age group as the subject used in the current study.

* The influence of variation of the contextual factors was examined to determine if the subject showed context sensitivity.

\section{Acoustic analysis 2: Vowel Formants}

The speech signal was received from the cassette tape and captured at a sampling rate of $10000 \mathrm{~Hz}$ (i.e. $0-4062$ $\mathrm{Hz}$ ) for analysis. The steady state of the vowel was marked with time cursors. A wideband spectrogram, as well as a linear prediction coding (LPC) formant history was obtained of the captured steady states of the respective productions of [a] and [o]. The mean value of formant 1,2 and 3 was obtained by means of the formant history statistics provided by the CSL.

The absolute formant values (mean value) of formant 1 , 2 and 3 of the respective productions of [a] and [0] were 
compared to the control data of Van der Merwe, et al. (1993) using non-parametric statistical analysis. In the study of Van der Merwe, et al., (1993) the formant patterns of the vowels of Afrikaans were studied. Ten males aged between 18 and 45 years, with no speech deficits and mother tongue speakers of Afrikaans, were selected. Formant frequency values of the same order were obtained from the ten subjects for all vowels. The overall conclusion was that reliable data was obtained.

The relative formant relationships of $\mathrm{F} 1 / 2, \mathrm{~F} 2 / 3$ and $\mathrm{F} 1 /$ 3 were also calculated and compared to the formant relationships found in normal speakers (Van der Merwe et al., 1993) using non-parametric statistical analysis to determine whether the current subject's formant relationships fall within normal intervals.

\section{Perceptual analysis 2: Intelligibility test}

Each panel member's score of the number of words correctly identified was individually calculated out of 20 and converted to a percentage. The type of error was also noted.

\section{RESULTS}

\section{FINDINGS OF THE SOPHISTICATED LISTENER PANEL REGARDING SYMPTOM PROFILE}

In order to determine if the subject belongs to either the diagnostic category of AOS or dysarthria, a sophisticated listener panel listened to a tape recorded sample of continuous speech. The finding was that, although highly intelligible, the subject could not be classified on the basis of salient perceptual features as either verbally apraxic or dysarthric. The subject displays symptoms from both diagnostic categories (see Table 2), but in a unique combination. Variable, often normal rate with inconsistent prolongations of phonemes occurred, together with inconsistent distortion in the spatial and temporal dimensions of utterances, particularly vowels, which appeared to be due to articulatory telescoping. The subject's speech cannot be categorised as the slow, struggling speech of an apraxic speaker, yet does not exhibit the constant distorted quality of dysarthric speech.

The conclusion was that the subject belongs to a unique category of neurogenic speech disorders. In order to describe and delineate this unusual speech disorder, the speech symptoms were further analyzed.

\section{ACOUSTIC ANALYSIS 1}

\section{Voice-onset-time (VOT)}

VOT was examined by categorising the articulation groups into the five sound structure groups - hereby determining whether context sensitivity was present in such a controlled sound structure environment and if such a controlled environment had any influence on the presence and possible type of error presented by the subject. The range of VOT scores are given in Table 3 . The subject's VOT ranges (smallest and biggest VOT measure of each unit) are compared to the normal range of $-180 \mathrm{msec}$ to $+15 \mathrm{msec}$.

In the category S1, three of the four articulation characteristic groups' VOT scores deviated from the normal range: A1 by $45 \mathrm{msec}$, and A3 and A4 both by $2 \mathrm{msec}$. In the category $\mathrm{S} 2$, two articulation characteristic groups' VOT deviated from the norm (A2 and A3), both with $2 \mathrm{msec}$. In sound structure categories S3, S4 and S5, all VOT scores of the articulation groups fell within normal limits. Fifteen of the twenty VOT scores ranged from -180 to $+15 \mathrm{msec}$, which is within normal limits. This represents normal VOT scores in $65 \%$ of all nonsense unit utterances. Four of the five errors are so marginal that they cannot be depicted as true VOT errors - which leaves one error. It can be explained by the fact that it was the first utterance produced by the subject and he could possibly have been rather anxious to articulate to the best of his ability.

The data seem to indicate that the subject rarely produces VOT's outside the normal range and also that those errors that did occur are to a certain extent context sensitive for variation in sound structure. Due to the low frequency of errors, it is not possible to make any final conclusions in this regard.

\section{Vowel duration (VD)}

The VD of the subject is displayed with articulation characteristics and sound structure groups in Table 4.

The general tendency seems to be longer than normal VD, with occasional normal VD and only one occurrence of shorter than normal VD. Because of only one shorter VD

TABLE 2: Salient features of AOS and dysarthria with the presence and absence of feature in speech of the subject

\begin{tabular}{|l|l|l|l|}
\hline APRAXIA OF SPEECH & SUBJECT & DYSARTHRIA & SUBJECT \\
\hline Slow struggling speech & absent & Slow speaking rate & absent \\
\hline Slow speaking rate & absent & Variable rate & present \\
\hline Inconsistent distortion & present & Consistent distortion & absent \\
\hline Spatial and temporal distortion & present & Short rushes of speech & absent \\
\hline Normal respiration and phonation & present & Respiration and phonation problems & absent \\
\hline Trial and error articulation & absent & Phonemes prolonged & present \\
\hline False starts and restarts & absent & Inappropriate silences & absent \\
\hline Prolongations & present & Monoloudness & absent \\
\hline Syllabic speech & absent & Articulatory telescoping & present \\
\hline
\end{tabular}


and inconsistent normal durations, no conclusions can be drawn regarding context sensitivity. The longer VD scores do not show any tendencies regarding either sound structure nor articulation characteristics.

Longer VD occurred in all sound structure groups across all articulatory groups with the exception of S1/A1, S2/A4, S5/A1 and S5/A4 which showed shorter, longer, normal and normal VD respectively. The frequent longer VD that occurred does not seem to be context sensitive as no clear pattern emerged from the results. Statistical analysis indicated that VD exceeded normal duration significantly.

\section{Utterance duration (UD)}

The UD of the subject is displayed with sound structure and articulation characteristics in Table 5.

The general tendency seemed to be toward longer than normal UD, with normal and shorter than normal UD occurring occasionally. Longer UD was represented in all sound structure groups across all articulation characteris- tic groups except with $\mathrm{S} 3 / \mathrm{A} 1$ and $\mathrm{A} 2$ (shorter than normal UD) and S4/A1, A2, A3 (normal UD was recorded). This observation was confirmed by statistical analysis. Shorter than normal and normal UD did occur, but it occurred inconsistently. Due to the small sample of analysis material of temporal speech characteristics, such as UD, it is not possible to make final conclusions in this regard.

\section{FINDINGS OF THE INTELLIGIBILITY RATINGS}

Intelligibility scores are displayed in Table 6.

The average intelligibility was calculated at $92,5 \%$ with scores of $80 \%, 85 \%, 95 \%, 100 \%$ and $100 \%$. Only nine words were perceived incorrectly out of 100 evaluations overall ( 20 words produced and evaluated by 5 panel members). Interrater comparisons revealed little differences between the intelligibility scores. It was therefore ascertained that the subject was highly intelligible.

The phonetic nature of the material aided description of errors. Two types of errors occurred:

TABLE 3: VOT results with ranges indicated

\begin{tabular}{|c|c|c|c|c|}
\hline $\begin{array}{l}\text { SOUND } \\
\text { STRUCTURE }\end{array}$ & $\begin{array}{l}\text { ARTICUL. } \\
\text { GROUP }\end{array}$ & UNIT & $\begin{array}{l}\text { RANGE OF } \\
\text { VOT (msec) }\end{array}$ & $\begin{array}{l}\text { NORMAL/ } \\
\text { DEVIANT }\end{array}$ \\
\hline \multirow[t]{4}{*}{ S1 } & A1 & babe & $-184,4-+56,25$ & Deviant with $45 \mathrm{msec}$ \\
\hline & $\mathrm{A} 2$ & bobe & $+7,81-+10.94$ & Normal \\
\hline & A3 & $\mathrm{dad} \varepsilon$ & $-37,5-+17,19$ & Deviant with $2 \mathrm{msec}$ \\
\hline & $\mathrm{A} 4$ & $\mathrm{~d} \jmath \mathrm{d} \varepsilon$ & $+10,94-+17,14$ & Deviant with $2 \mathrm{msec}$ \\
\hline \multirow[t]{4}{*}{$\mathrm{S} 2$} & $\mathrm{~A} 1$ & bat $\varepsilon$ & $+6,25-+14,06$ & Normal \\
\hline & $\mathrm{A} 2$ & bot $\varepsilon$ & $+9,37-+17,19$ & Deviant with $2 \mathrm{msec}$ \\
\hline & A3 & dake & $+10,94-+17,19$ & Deviant with $2 \mathrm{msec}$ \\
\hline & A4 & $\mathrm{d} \jmath \mathrm{k} \varepsilon$ & $+4,68-+10,94$ & Normal \\
\hline \multirow[t]{4}{*}{ S3 } & $\mathrm{A} 1$ & batef & $+3,25-+10,94$ & Normal \\
\hline & A2 & botef & $+10,94-+12,50$ & Normal \\
\hline & $\mathrm{A} 3$ & dakef & $+10,94-+15,63$ & Normal \\
\hline & $\mathrm{A} 4$ & dokef & $+9,37-+15,63$ & Normal \\
\hline \multirow[t]{4}{*}{$\mathrm{S} 4$} & $\mathrm{~A} 1$ & bat & $+7,81-+10,94$ & Normal \\
\hline & A2 & bot & $+4,68-+7,81$ & Normal \\
\hline & A3 & dak & $+12,50-+14,06$ & Normal \\
\hline & A4 & dok & $+10,94-+15,63$ & Normal \\
\hline \multirow[t]{4}{*}{ S5 } & $\mathrm{A} 1$ & batefup & $0-+15,63$ & Normal \\
\hline & A2 & botefup & $+7,81-+12,50$ & Normal \\
\hline & $\mathrm{A} 3$ & dakefup & $+10,94 \cdot+14,06$ & Normal \\
\hline & A4 & dokefup & $+10,94-+15,63$ & Normal \\
\hline
\end{tabular}


An Exploratory Study of an Undefined Acquired Neuromotor Speech Disorder within the Context of the Four Level Framework for Speech Sensorimotor Control

TABLE 4: Vowel duration results with contextual factors sound structure and articulation characteristics indicated

\begin{tabular}{|c|c|c|c|c|c|}
\hline $\begin{array}{l}\text { SOUND } \\
\text { STRUCTURE }\end{array}$ & $\begin{array}{l}\text { ARTICUL. } \\
\text { GROUP }\end{array}$ & UNIT & VD OF CONTROL & VD OF SUBJECT (IN msec) & $\begin{array}{l}\text { COMPARISON USING } \\
\text { NON-PARAMETRIC } \\
\text { STATISTICAL } \\
\text { ANALYSIS } \\
\end{array}$ \\
\hline \multirow[t]{4}{*}{$\mathrm{S} 1$} & A1 & babe & $136148 \quad 153153$ & $\begin{array}{lllll}118.7 & 114.1 & 85.9 & 171.9 & 35.9\end{array}$ & shorter \\
\hline & $\mathrm{A} 2$ & b sbe & 116111117117 & $135.9125 \quad 132.8135 .9129 .7$ & longer \\
\hline & A3 & $\mathrm{dad} \varepsilon$ & 140144144159 & 159.4184 .4190 .6198 .4190 .6 & longer \\
\hline & A4 & $\mathrm{d} \supset \mathrm{d} \varepsilon$ & 123121119120 & 148.4159 .4159 .4148 .4178 .1 & longer \\
\hline \multirow[t]{4}{*}{$\overline{\mathrm{S} 2}$} & A1 & bat $\varepsilon$ & 116123123123 & $\begin{array}{lllll}139.1 & 129.7 & 120.3 & 123.4 & 134.4\end{array}$ & longer \\
\hline & A2 & bot $\varepsilon$ & 109112121116 & $126.6115 .6139 .1134 .4 \quad 107.8$ & normal \\
\hline & $\mathrm{A} 3$ & $\operatorname{dak} \varepsilon$ & 106112119120 & $139.1 \quad 132.8132 .8121 .9123 .4$ & longer \\
\hline & $\overline{\mathrm{A} 4}$ & $\operatorname{dok} \varepsilon$ & $100112119 \quad 92$ & $151.6 \quad 135.9134 .4132 .8134 .4$ & longer \\
\hline \multirow[t]{4}{*}{$\overline{\mathrm{S} 3}$} & A1 & batef & 114107112116 & $117.2121 .9125 \quad 109.4 \quad 131.2$ & longer \\
\hline & $\mathrm{A} 2$ & botef & $116112102 \quad 98$ & $135.9153 .1 \quad 173.1 \quad 151.6 \quad 162.5$ & longer \\
\hline & A3 & dakef & 111111111114 & 134.4123 .4117 .2126 .6121 .9 & longer \\
\hline & A4 & dokgf & 98112112101 & 140.6140 .6140 .6153 .1135 .9 & longer \\
\hline \multirow[t]{4}{*}{$\overline{\mathrm{S}} 4$} & $\mathrm{~A} 1$ & bat & \begin{tabular}{|l|l|l}
144150150139 \\
\end{tabular} & $\begin{array}{llllll}150 & 168.7 & 156.3 & 153.1 & 157.8 \\
\end{array}$ & longer \\
\hline & $\mathrm{A} 2$ & bot & 136133140125 & $168.7173 .4 \quad 160.9164 .1 \quad 168.7$ & longer \\
\hline & A3 & dak & 112109128128 & 190.6185 .9170 .3168 .7182 .8 & longer \\
\hline & A4 & dok & 125127123128 & $181.2 \quad 190.6 \quad 182.8 \quad 181.2178 .1$ & longer \\
\hline \multirow[t]{4}{*}{ S5 } & $\mathrm{A} 1$ & batefup & $1 2 2 1 2 2 \longdiv { 1 1 7 1 2 7 }$ & 118.7128 .1109 .4109 .4106 .2 & normal \\
\hline & $\mathrm{A} 2$ & botefup & $\begin{array}{|llll|}106 & 89 & 92 & 100 \\
\end{array}$ & 134.4134 .4148 .4170 .3139 .1 & longer \\
\hline & A3 & dakefup & 103120107103 & 132.8137 .5132 .8115 .6123 .4 & longer \\
\hline & $\mathrm{A} 4$ & dokefup & $108109 \quad 97105$ & $\overline{106.2129 .7110 .9101 .6121 .9}$ & normal \\
\hline
\end{tabular}

TABLE 5: Utterance duration results with contextual factors sound structure and articulation characteristics indicated

\begin{tabular}{|c|c|c|c|c|c|}
\hline $\begin{array}{l}\text { SOUND } \\
\text { STRUCTURE }\end{array}$ & $\begin{array}{l}\text { ARTICUL. } \\
\text { GROUP }\end{array}$ & UNIT & VD OF CONTROL & VD OF SUBJECT (IN msec) & $\begin{array}{l}\text { COMPARISON USING } \\
\text { NON-PARAMETRIC } \\
\text { STATISTICAL } \\
\text { ANALYSIS } \\
\end{array}$ \\
\hline \multirow[t]{4}{*}{$\$ 1$} & A1 & $\mathrm{bab} \varepsilon$ & 512.5523589564 & 764.1754 .7564 .1643 .7700 & longer \\
\hline & $\mathrm{A} 2$ & bobe & $\begin{array}{|ll|}562 \quad 717728525 \\
\end{array}$ & 639.1723 .4498 .4701 .6687 .5 & longer \\
\hline & $\mathrm{A} 3$ & $\mathrm{dad} \varepsilon$ & $344 \quad 397428464$ & \begin{tabular}{|l}
681.2670 .9821 .9771 .9798 .4 \\
\end{tabular} & longer \\
\hline & $\mathrm{A} 4$ & $\mathrm{~d} \supset \mathrm{d} \varepsilon$ & $428 \quad 448455433$ & 712.5764 .1754 .7754 .7750 & longer \\
\hline \multirow[t]{4}{*}{$\mathrm{S} 2$} & $\mathrm{~A} 1$ & bate & $447 \quad 472575584$ & 698.4704 .7687 .5689 .1701 .6 & longer \\
\hline & $\mathrm{A} 2$ & bote & 412.5414527528 & 662.5695 .3701 .6712 .5570 .3 & longer \\
\hline & A3 & dake & $\begin{array}{|ll|}317 & 420409450 \\
\end{array}$ & 623.4632 .8659 .4645 .3682 .8 & longer \\
\hline & A4 & dok $\varepsilon$ & $395 \quad 589553592$ & 612.5598 .4614 .1626 .6631 .2 & longer \\
\hline \multirow[t]{4}{*}{$\mathrm{S} 3$} & $\overline{\mathrm{A} 1}$ & batef & $534 \quad 547561616$ & 482.8484 .4498 .4498 .4451 .6 & shorter \\
\hline & $\mathrm{A} 2$ & bottef & $527 \quad 561570494$ & \begin{tabular}{|l}
504.7512 .5 \\
\end{tabular} & shorter \\
\hline & $\mathrm{A} 3$ & dakef & $350 \quad 417 \quad 402422$ & 528.1548 .4546 .9529 .7506 .2 & longer \\
\hline & $\mathrm{A} 4$ & dokef & \begin{tabular}{|ll}
$409 \quad 408489425$ \\
\end{tabular} & 495.3520 .3523 .4537 .5526 .6 & longer \\
\hline \multirow[t]{4}{*}{$\mathrm{S} 4$} & $\mathrm{~A} 1$ & bat & 312.5320484325 & 379.7410 .9379 .7351 .6398 .4 & normal \\
\hline & $\mathrm{A} 2$ & bot & $\begin{array}{|lr|}327 & 502494325 \\
\end{array}$ & 404.7403 .1390 .6406 .3406 .3 & normal \\
\hline & A3 & dak & $272 \quad 411319406$ & 404.7398 .4367 .2387 .5392 .2 & normal \\
\hline & $\mathrm{A} 4$ & dok & \begin{tabular}{|ll}
320 & 366306319 \\
\end{tabular} & $\begin{array}{|lll|}418.7421 .9 & 403.1375 & 365.6 \\
\end{array}$ & normal \\
\hline \multirow[t]{4}{*}{ S5 } & $\mathrm{A} 1$ & batefup & $464 \quad 494436478$ & 381.2364 .1331 .2364 .1373 .4 & shorter \\
\hline & $\mathrm{A} 2$ & botefup & $333 \quad 451417350$ & \begin{tabular}{|lll}
456.2 & 493.7476 .6475 & 484.4 \\
\end{tabular} & longer \\
\hline & $\mathrm{A} 3$ & dakefup & $\begin{array}{|lr|}452 & 334334353 \\
\end{array}$ & 426.6437 .5454 .7443 .7434 .4 & longer \\
\hline & $\mathrm{A} 4$ & dokefup & $353 \quad 353344314$ & 403.1421 .9404 .7415 .6418 .7 & longer \\
\hline
\end{tabular}


* Continuants were perceived as plosives in $55 \%$ of all errors.

* Initial devoiced consonants were perceived as voiced in $44 \%$ of the occurring errors.

Although the errors give some insight into the phonetic nature of the problem, the error scores are marginally small.

The semi-sophisticated listener panel members, who had no background information on the case, perceived the subject as a second language speaker or a clutterer when they were asked for a subjective diagnostic interpretation of his speech. They perceived his vowels to be more deviant from normal production than his consonants and the [a] and [o] as particularly deviant.

\section{FORMANT ANALYSIS OF DISTORTED VOWELS}

The decision to analyze vowels was based on both the sophisticated and the semi-sophisticated listener panels' observation that the subject's production is deviant from

TABLE 6: Scores obtained by the semi-sophisticated listener panel in the intelligibility rating

\begin{tabular}{|l|l|l|}
\hline $\begin{array}{l}\text { Listener Panel } \\
\text { panel } \\
\text { member (LPM) }\end{array}$ & $\begin{array}{l}\text { Score out } \\
\text { of } 20\end{array}$ & Percentage \\
\hline LPM 1 & 16 & $80 \%$ \\
\hline LPM 2 & 17 & $85 \%$ \\
\hline LPM 3 & 19 & $95 \%$ \\
\hline LPM 4 & 19 & $95 \%$ \\
\hline LPM 5 & 20 & $100 \%$ \\
\hline LPM 6 & 20 & $100 \%$ \\
\hline
\end{tabular}

normal Afrikaans mother tongue speakers' vowel production and more so than his consonant production. The vowels identified as being most deviant were the [a] and [0]. The first three formant frequencies of [a] were analyzed on six productions and [0] on five productions of the sound in similar contexts.

The average formant frequency values of the current subject's production of [a] and [o] are displayed in Table 7 and 8 respectively.

The data obtained is characteristic of the subject's [a] and [0] production in continuous speech. A comparison of the average formant frequency values of Van der Merwe et al. (1993) (the control group) and the current subject is displayed in Table 9 for [a] and in Table 10 for [0].

In the selected productions of [a] by the subject (see Table 7 and 9 ), the following was observed:-

- The formant frequency values of formant 1 (F1) lie between $515.4 \mathrm{~Hz}$ and $760.3 \mathrm{~Hz}$ with an average value of $638.4 \mathrm{~Hz}$. The control group's values for formant 1 of [a] range from $521.7 \mathrm{~Hz}$ to $778.7 \mathrm{~Hz}$ with the average value for formant frequency 1 calculated at $697.2 \mathrm{~Hz}$. Using non-parametric analysis, no significant difference between the subject and the control data could be found. Although the subject's F1 falls within normal limits with non-parametric statistical analysis, there is some variability in the respective values obtained. For productions of AAN, the values varied between $744.2 \mathrm{~Hz}$ and 760.3 $\mathrm{Hz}$ (a difference of $16 \mathrm{~Hz}$ ). In AANDETE, the value lowered to $515.4 \mathrm{~Hz}$ which is more than $200 \mathrm{~Hz}$ lower.

- The formant frequency values of formant 2 (F2) of the subject lie between $1260.1 \mathrm{~Hz}$ and $1571.6 \mathrm{~Hz}$ with the average frequency value for $\mathrm{F} 2$ of [a] calculated at 1421.2 $\mathrm{Hz}$. The frequency values for formant 2 of the control group range from $924.1 \mathrm{~Hz}$ and $1295.6 \mathrm{~Hz}$ with the average calculated at $1113.7 \mathrm{~Hz}$. According to non-parametric statistical analysis, the subject's mean for $\mathrm{F} 2$ was significantly higher than the median of the control group. The variability in formant values continued in $\mathrm{F} 2$ with AAN 1 and AAN 2 obtaining values of 1571.6 and 1443.2

TABLE 7: The formant frequencies of six productions of [a] in similar phonetic contexts

\begin{tabular}{|l|c|c|c|c|c|c|}
\hline & \multicolumn{7}{|c|}{ FORMANT FREQUENCY IN Hz FOR SIX PRODUCTIONS } \\
\hline FORMANTS & aandete & aan 1 & aan 2 & gaan & daar 1 & daar 2 \\
\hline Formant 1 & 515.4 & 744.2 & 760.3 & 539.6 & 655.9 & 615.1 \\
\hline Formant 2 & 1260.1 & 1571.6 & 1443.2 & 1559.6 & 1377.1 & 1315.7 \\
\hline Formant 3 & 2564.0 & 2872.4 & 2680.9 & 2840.0 & 2575.0 & 2479.8 \\
\hline
\end{tabular}

TABLE 8: The formant frequencies of five productions of [ ] in similar phonetic contexts

\begin{tabular}{|l|c|c|c|c|c|}
\hline & \multicolumn{6}{|c|}{ FORMANT FREQUENCY IN Hz FOR FIVE PRODUCTIONS } \\
\hline Formants & samekoms & kom & word & rok & ongemaklik \\
\hline Formant 1 & 480.7 & 478.8 & 503.9 & 662.6 & 585.8 \\
\hline Formant 2 & 1982.9 & 1738.9 & 1006.7 & 1557.6 & 1975.2 \\
\hline Formant 3 & 3314.3 & 3027.3 & 2472.0 & 2662.7 & 2825.0 \\
\hline
\end{tabular}


$\mathrm{Hz}$ respectively - a difference of $128 \mathrm{~Hz}$. There is a difference of $61 \mathrm{~Hz}$ between values obtained for DAAR.

- The formant frequency values of formant 3 (F3) of the subject's production of [a] lie between $2564.0 \mathrm{~Hz}$ and $2872.5 \mathrm{~Hz}$ with the average calculated at $2668.2 \mathrm{~Hz}$. In the control group, formant 3 values of [a] range from $2213.6 \mathrm{~Hz}$ and $2798.1 \mathrm{~Hz}$ with the average calculated at $2479.8 \mathrm{~Hz}$. Non-parametric statistical analysis showed that the median of the subject was significantly higher. F3 showed more variability in values obtained for AAN 1 and AAN $2: 2872.4 \mathrm{~Hz}$ and $2680.0 \mathrm{~Hz}$ respectively. The difference between those two calculate to almost 200 $\mathrm{Hz}$. The value of DAAR $1(2575 \mathrm{~Hz})$ and DAAR $2(2479.8$ $\mathrm{Hz}$ ) differed by $95 \mathrm{~Hz}$.

In the selected productions of [0], (see table 8 and 10) the following were observed:-

- The formant frequency values obtained for formant 1 (F1) of the subject, lie between $478.9 \mathrm{~Hz}$ and $662.6 \mathrm{~Hz}$ with the average calculated at $542.3 \mathrm{~Hz}$. In the control group, formant frequency values for $\mathrm{F} 1$ range from 298.8 $\mathrm{Hz}$ to $433.6 \mathrm{~Hz}$ with the average calculated at $373.8 \mathrm{~Hz}$. No identical words could be used for formant analysis of [0]. Three of the five productions contained [0] followed by a nasal sound : SAMEKOMS, KOM, ONGEMAKLIK with their $F 1$ values of [o] respectively $480.7,478.8$ and $585.8 \mathrm{~Hz}$. Even though SAMEKOMS and KOM differed in number of syllables, their formant values of [o] differ with just more than $2 \mathrm{~Hz}$. However, $\mathrm{F} 1$ of [o] in ONGEMAKLIK differ from them both by almost $100 \mathrm{~Hz}$.

- Formant 2 (F2) values of the subject lie between 1006.8 $\mathrm{Hz}$ and $1982.9 \mathrm{~Hz}$ with the average calculated at 1652.3 $\mathrm{Hz}$. In the control group, values of F2 of [0] range from $708.2 \mathrm{~Hz}$ to $942.8 \mathrm{~Hz}$ with the average calculated at 805.6 $\mathrm{Hz}$. F2 of [0] followed by a nasal sound were $1982.9 \mathrm{~Hz}$ (SAMEKOMS), $1738.9 \mathrm{~Hz}$ (KOM) and $1975.2 \mathrm{~Hz}$ (ONGEMAKLIK). The F2 values for production of SAMEKOMS and ONGEMAKLIK, the three syllabic words, were closer and both of them differed considerably from the value of [ 0 ] in KOM at $1738.9 \mathrm{~Hz}, 200 \mathrm{~Hz}$ below their value.

- The formant frequency values of formant 3 of [o] of the subject lie between $2472.0 \mathrm{~Hz}$ and $3314.3 \mathrm{~Hz}$ with the average calculated at $2860.2 \mathrm{~Hz}$. In the control group, formant frequency valuesirange from $1991.2 \mathrm{~Hz}$ to 2754.4 $\mathrm{Hz}$ with the average calculated at $2333.3 \mathrm{~Hz}$. The values of $\mathrm{F} 3$ in the productions of [ $[$ ] followed by a nasal sound, the values obtained were respectively 3314.3 (SAMEKOMS), 3027.3 (KOM) and 2825.0.(ONGEMAK-

TABLE 9: Average formant frequencies (in $\mathrm{Hz}$ ) of the control data and the subject of [a]

\begin{tabular}{|l|l|l|}
\hline & \multicolumn{2}{|c|}{$\begin{array}{r}\text { CALCULATED AVERAGE } \\
\text { FORMANT FREQUENCY (Hz) }\end{array}$} \\
\hline FORMANTS & CONTROL DATA & SUBJECT \\
\hline Formant 1 & 679.2 & 638.4 \\
\hline Formant 2 & 1113.7 & 1421.2 \\
\hline Formant 3 & 2479.8 & 2668.2 \\
\hline
\end{tabular}

LIK) $\mathrm{Hz}$. The first two values of [0] differ with $300 \mathrm{~Hz}$ and the first and the latter with $500 \mathrm{~Hz}$. The values obtained for [0] in ROK $(2662.7 \mathrm{~Hz})$ and WORD (2472.0 $\mathrm{Hz}$ ) also vary considerably. With $\mathrm{F} 1,2$ and 3 , the median of the formant values of the subject was significantly higher than the median and formant values of the control group in production of [0].

\section{DISCUSSION}

The study aimed to collect exploratory data on the speech of a subject with an undefined acquired neuromotor speech disorder. The initial findings indicate that the subject displays a unique combination of symptoms, different from both AOS and dysarthria, namely inconsistent distortion of temporal and spatial dimensions, prolongations, variable rate and articulatory telescoping. These are all symptoms of neuromotor speech disorders which also occur in AOS and dysarthria. However, they occurred in the absence of the core or salient features of these two disorders, namely slow effortfull speech with self-initiated attempts to correct errors, false starts and restarts, substitutions and distorted substitutions which is characteristic of AOS according to most current authors and muscle tone disorders and involuntary movements which affects articulation, respiration, phonation, resonance and sometimes vegetative functions as well.

Despite the above characteristics, the subject was perceived as highly intelligible. There were no clear tendencies that could be identified in the speech of the subject on examination of the temporal features. The duration measurements (vowel and utterance) revealed longer than normal duration, however, the utterances were not perceived by the listeners as abnormally long. One can possibly attribute the longer durations to the nature of the material used. The nonsense syllables could facilitate careful productions. No conclusions can be drawn with regard to VOT due to the rare occurrence of errors. The temporal features also showed no clear tendencies with regard to context sensitivity. This is contrary to the findings for AOS, Cerebellar Dysarthria and Lower Motor Neuron Dysarthria which displayed diverse patterns of context sensitivity (Van der Merwe, 1986; Brittz, 1994; Van der Merwe, et al., 1995). However, the lack of context sensitivity, might be characteristic of this particular disorder. This particular issue needs further research before any conclusions can be reached.

The distorted quality in the subject's speech could not be explained by VOT errors as they rarely occurred. The extended VD and UD might have contributed to the per-

TABLE 10: Average formant frequencies (in $\mathrm{Hz}$ ) of the control data and the subject of [ ]

\begin{tabular}{|l|l|l|}
\hline & \multicolumn{2}{|c|}{$\begin{array}{r}\text { CALCULATED AVERAGE } \\
\text { FORMANT FREQUENCY }(\mathrm{Hz})\end{array}$} \\
\hline FORMANTS & CONTROL GROUP & SUBJECT \\
\hline Formant 1 & 373.8 & 542.3 \\
\hline Formant 2 & 805.6 & 1652.3 \\
\hline Formant 3 & 2333.2 & 2860.2 \\
\hline
\end{tabular}


ception of distortion in speech production. The formant analysis, however, revealed more about the subject's particular speech pattern. Despite the high intelligibility, there was a combination of acoustic features in the vowels that were not characteristic of normally produced Afrikaans vowels in a similar phonetic context. Inconsistent distortions occurred due to inaccurate direction and range of movement. Firstly, absolute formant values of F1, F2 and F3 varied considerably between productions. The first formant is most responsive to changes in mouth opening. Speech sounds requiring small mouth openings have low frequency first formants. Conversely, open mouth sounds are characterised by relatively high first frequency formants (Borden, Harris \& Raphael, 1994). While the subject's first formants are quite low in comparison to the controls, it can be proposed that the subject has a relatively small opening of the mouth for [a] and [0] which are back vowels and that possibly require relatively greater mouth opening.

The second formant is most responsive to changes in the oral cavity. Tongue backing or lip activity might lower the frequency of this formant, as these conditions occur in areas of high velocity, but any tongue or jaw movement which would narrow the region in the oral cavity, where the pressure is relatively high, would result in raising the frequency of the second formant (Borden et al., 1994). As the subject's second formant values are higher than those of the control group, a possible explanation can be a too narrow region in the oral cavity due to excessive jaw and/or lip activity while producing [a] and [0].

The third formant is responsive to front versus back constriction of the articulators (Borden et al., 1994), with the subject showing consequent difficulty in this area. This confirms the subject's difficulty with the relative mouth opening, oral cavity space and front versus back constriction of the articulators. This limited range of movement could contribute to the articulatory telescoping present in the subject's speech.

Vowels are perceptually differentiated according to the ratio of relationships between formant frequencies F1, F2 and F3 and not their absolute values (Minifie, Hixon \& Williams, 1973). The $\mathrm{F} 1 / \mathrm{F} 2$ relationship is the most important for the perception of vowels (Minifie et al., 1973). This does not imply that the interpersonal differences in formant relationships do not occur, but these differences should vary within the degrees of freedom or equivalence barriers (Sharkey \& Folkins, 1985). With regard to formant relationships for [a], statistical analysis indicated deviant $F 1 / 2$ and $F 2 / 3$ relationships with only $F 1 / 3$ falling within normal criteria. The typical coarticulatory patterns found in Afrikaans, provide a possible explanation for the [a] sounding better than acoustic analysis indicated. With [0], F1/2 and $\mathrm{F} 1 / 3$ fall within normal intervals, even though the absolute formant frequencies showed deviation from the norm. The F2/3 deviated from the norm. It can therefore be assumed that the deviant formant relationships that did occur, led to the perception of distorted vowel quality and not misperception of the vowel as being another vowel.

But dominating the subject's symptom profile, and possibly underlying it, is the distortion of spatial and temporal dimensions in his speech. The distortion in vowel quality, the variable segmental duration and occasional errors in interarticulator synchronisation, could possibly be attributed to a disorder in motor programming of tone, rate, direction and range of movement (Van der Merwe, 1997). The finding that these symptoms occurred inconsistently might confirm this hypothesis. The unique combination of symptoms as found in this subject, might constitute one form of a pure motor programming speech disorder.

The observation made by the listener panels that the subject sounded like a second language speaker, which he is not, is perhaps significant. In the literature, mention is made of a Foreign Accent Syndrome which is an acquired neurogenic disorder (Blumstein, Alexander, Ryalls, Katz \& Dworetzky, 1987; Takayama, Sugishita, Kido, Ogawa, \& Akiguchi, 1993). It is possible that this case is an example of this syndrome. Similar abnormalities in vowel production was identified in these cases. The basis of this syndrome, however, needs careful further research.

The true nature of disorders in motor programming as postulated by the Four Level Framework (Van der Merwe, 1997) needs to be clarified by future research. All possible cases should be studied with regard to site of lesion and symptomatology (acoustic and perceptual). The Four Level Framework (Van der Merwe, 1997) should be considered as a basis for the comparison of the symptoms in these cases with that of other neuromotor disorders as a guide to a better understanding of the complex nature of acquired neurogenic communication disorders. The Four Level Framework developed by Van der Merwe (1997), offers a novel view on neurogenic communication disorders, generating new questions to be answered by future research in the hope that "our gained insight will consequently assist in optimising clinical assessment and intervention" (Van der Merwe, 1997 : 19).

\section{REFERENCES}

Allen, G.I. \& Tsukahara, N. (1974). Cerebrocerebellar communication systems. Physiological Reviews, 54, 957-997.

Blumstein, S.E., Alexander, M.P., Ryalls, J.H., Katz, W. \& Dworetzky, B. (1987). On the nature of the Foreign Accent Syndrome: A Case Study. Brain and Language, 31, 215-244.

Borden, G.J., Harris, K.S. \& Raphael, L.J. (1994). Speech Science Primer (3rd ed). Baltimore: Williams \& Wilkins.

Brittz, H.C. (1994). Die invloed van kontekstuele fahtore op sekere temporale parameters in disartriese spraak: 'n vergelyking tussen serebellêre en onderste motor neuron disartrie. Unpublished B. Communication Pathology research report. University of Pretoria.

Brooks, V.B. (1986). The neural basis of motor control. New York: Oxford University Press.

Darley, F.L., Aronson, A.E., \& Brown, J.R. (1975). Motor Speech Disorders. Philadelphia: W.B. Saunders Company.

Gay, T. (1979). Coarticulation in some consonant-vowel and consonant cluster vowel syllables. In B. Lindblom \& S. Ohman (Eds). Frontiers of Speech Communication Research. London: Academic Press.

Ingrisano, D. \& Weismer, G. (1979). [s] duration: methodological influences and linguistic variables. Phonetica, 36, 32-43.

Itoh, M. \& Sasanuma, S. (1984). Articulatory movements in apraxia of speech. In J.C. Rosenbek, M.R. McNeil \& A.E. Aronson (Eds.). Apraxia of speech: Physiology, acoustics, linguistics and management. San Diego: College-Hill Press.

Kent, R.D. \& Rosenbek, J.C. (1983). Acoustic patterns in apraxia of speech. Journal of Speech and Hearing Research, 26, 231249.

Kertesz, A. (1982). Western Aphasia Battery. Grune \& Stratton: New York.

Klopper, K. (1983). Spraakverstaanbaarheid by Afrikaanse disartriese sprekers:'n Voorgestelde toets. Unpublished B.Communi- 
cation Pathology research report. University of Pretoria.

painte, L.L. (1982). Neurogenic disorders of speech. In G.H Shames \& D.H. Wigg (Eds.). Human communication disorders: an introduction. Columbus: Charles E. Merril Publishing Company.

Lisker, L. \& Abrahamson, A.A. (1964). A cross-language study of voicing in initial stops: Acoustic measurements. Word, 20, 384422.

Marsden, C.D. (1984). Which motor disorder in Parkinson's Disease indicates the true motor function of the Basal Ganglia? In: Ciba Foundation Symposium 107. Functions of the Basal Ganglia. London: Pitman.

McNeil, M.R. \& Kent, R.D. (1987). Relative timing of sentence repetition in apraxia of speech and conduction aphasia. In: J.H. Ryalls (ed.). Phonetic approaches to speech production in aphasia and related disorders. Boston: College-Hill, Little Brown and Company.

McNeil, M.R., Robin, D.A. \& Schmidt, R.A. (1997). Apraxia of speech: Definition, differentiation, and treatment. In M.R. McNeil (ed) Clinical Management of Sensorimotor Speech Disorders. New York: Thieme Medical Publishers.

Minifie, F.D., Hixon, T.J. \& Williams, F. (1973). Normal aspects of speech, hearing and language. New Jersey: Prentice-Hall.

Prutting, C.A. \& Kirschner, D.M., in T.M. Gallagher \& C.A. Prutting (1983). Pragmatic assessment and intervention issues in language. College-Hill Press, Inc.: San Diego.

Sharkey, S.G. \& Folkins, J.W. (1985). Variability of lip and jaw movements in children and adults: Implications for the development of speech motor control. Journal of Speech and Hearing Research, 28, 8-15.

Takayama, Y., Sugishita, M., Kido, T., Ogawa, M. \& Akiguchi, I. (1993). A case of foreign accent syndrome without aphasia caused by a lesion of the left precentral gyrus. Neurology, 43, 1361-2.

Van der Merwe, A. (1985). Disartrie-ondersoekvorm. Universiteit van Pretoria.

Van der Merwe, A. (1986). Die motoriese beplanning van spraak by verbale apraksie. Unpublished D.Phil Dissertation. University of Pretoria.

Van der Merwe, A., Groenewald, E., Van Aardt, D., Tesner, H.E.C. \& Grimbeek, R.J. (1993). Die formantpatrone van Afrikaanse vokale soos geproduseer deur manlike sprekers. South African Journal of Linguistics, 11(2), 71-79.

Van der Merwe, A., Groenewald, E., Brittz, H.C. \& Grimbeek, R.J. (1995). Differentiating the levels of dysfunction in acquired neuromotor speech disorders: the context sensitivity of temporal features in apraxia of speech, cerebellar dysarthria and lower motor neuron dysarthria. Proceedings of the British Aphasiology Society Biennial International Conference 12th - 14th September 1995, p. 16.

Van der Merwe, A. (1997). A theoretical framework for the characterization of pathological speech sensorimotor control. In M.R. McNeil (Ed.). Clinical management of sensorimotor speech disorders. New York: Thieme Medical Publishers.

Yorkston, K.M., Beukelman, D.R. \& Bell, K.R. (1988). Clinical Management of Dysarthric Speakers. Texas: Pro-Ed. 


\section{OUR REAL PROBLEM IS IN THE HEARTS AND MINDS OF MEN.}

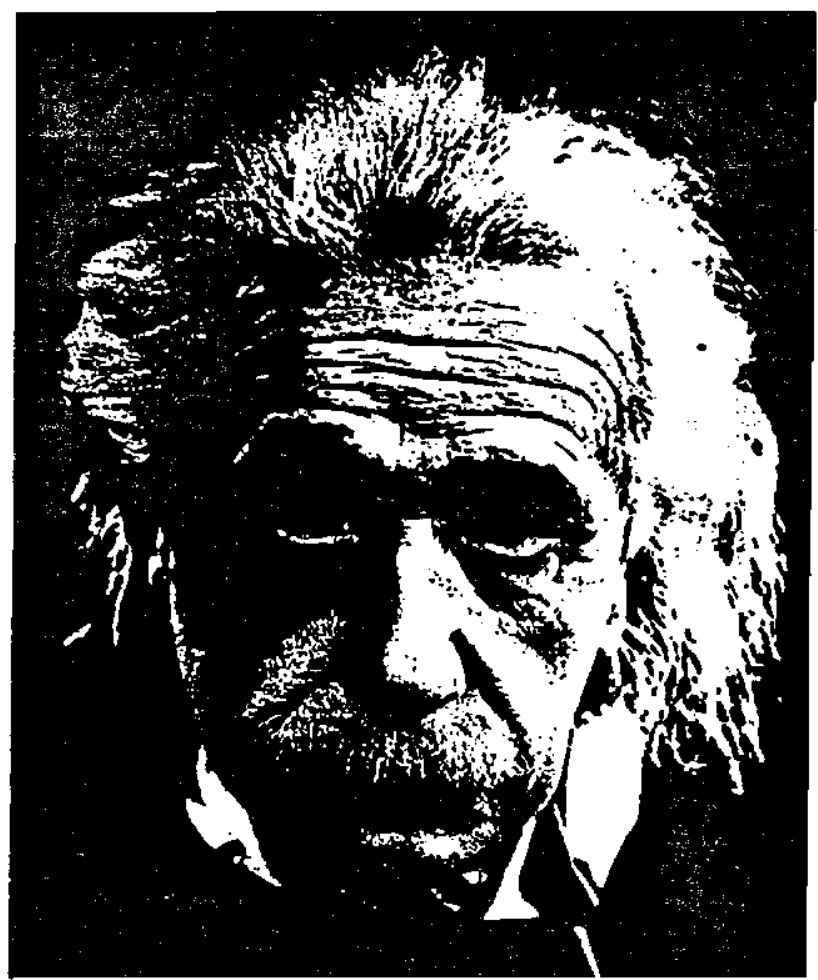

Our real problem is in the hearts and minds of men.

It is not a problem of Physics but of Ethics

Man's skills has outstripped his morals.

His engineering has leaped ahead of his wisdom.

We cannot cancel or call back his scientific advances,

but we CAN, and we MUST,

if the world is to survive, help man to catch up.

In GOD's name, if you still believe in GOD. Take HIM seriously,

and somehow get control of what science has given the world,

or else we shall likewise perish!"

\section{Albert Einstein.}

\section{Do you face Advancing} Technology with apprehension and a little fear?

This need not be! - if you have a supplier who will help you all the way! For more than 20 years Teknimed have brought the latest and most advanced solutions out of an enormous range of Hearing Health Care Products to Dispensers, Schools, ENT Specialists and Hospitals all over

South Africa. We do everything to make your task as painless as possible by providing our very best product, service, price, training and after-sales service. From anything like a simple earlight, to custom acoustic enclosures, you can rely on us to give you an efficient and honest service! If you would like to find our more about what our team of specialists can do for you, write - phone - fax or Email us at:

\section{TEKNIMED ENTERPRISES cc}

P O Box 662, SOMERSET WEST, 7129

Tel 021-852 1619. Fax 021-851 3833. E-mail: teknimed@ilink.nis.za 